\title{
Discussion on the Experimental Creative Sketch Teaching
}

\author{
Hui Li \\ School of Art and Design \\ Huanghe Science and Technology College \\ Zhengzhou, Henan, China 450063
}

\begin{abstract}
Sketch is an important basic subject of art education in universities. This paper analyzes the current situation of sketch teaching and the necessity of the experimental creative sketch teaching and introduces ways of experimental sketch teaching as well as the formation of creative style.
\end{abstract} form

Keywords - experimental; creativity; creative form; meaningful

\section{INTRODUCTION}

The major of art and design is an interdisciplinary subject focusing on the art theory. Particularly, the major of art and design with modern significance refers to the professional and marginal subject that integrates technology and art. It requires the creators must have a comprehensive modeling ability. The acquisition of ability is closely linked to the sketch teaching of basic design. The sketch training is the essential way to acquire the ability. The diversification of art has involved in the art education field and had great impact on the traditional sketch teaching mode. The sketch reform has become an important part of the art education reform in universities. This paper deeply analyzes the implementation background, contents and forms of the experimental creative sketch teaching, in order to enlighten the sketch teaching in our country at present.

\section{DEFINITION OF THE EXPERIMENTAL CREATIVE SKETCH}

Just as its name implies, the creativity refers to the creative idea, understood as the imagination and conception with creative meaning. The essence of design is creativity. "The creativity refers to create it initially." (Han Shu, Xu Zhuan Xia, Yan Shigu notes). The creativity has perceptual color but depends on the rational cognitive process. The experimental creative sketch depends on the building of the creative imagery thinking model, namely cognizing and perceiving the nature, creating the perceptual aesthetic environment and new things. Creativity is the core of design. Although perceptual, it is the motive power of design. The imaginary thinking with the time significance will be created through rational cognition, experience and comprehension.

The experimental creative sketch is to express the creation intention, focuses on the design and uses creative thinking mode to research, understanding and associating; it expands the visual experience, stimulates students' creativity and expands the thinking space, and then changes the thinking from the basic teaching to the design teaching, in order to make a breakthrough on the basis of tradition.

\section{THE NECESSITY OF EXPERIMENTAL CREATIVE SKETCH TEACHING AND THE RECONSIDERATION ON THE CURRENT SituATION OF SKETCH TEACHING}

According to the basic sketch teaching of the art and design major in universities at present, it shows most follow the teaching contents and forms of basic sketch on the modified modeling art of traditional painting. Compared with the allaround expression form of design art, no matter on the teaching contents or forms, the traditional sketch teaching model cannot adapt to the teaching of art and design major, so the basic sketch teaching of the art and design major has little relationship with the professional teaching. Students of art and design major cannot acquire the essential modeling ability corresponding to the skill training in the specialized course comprehensively. It impedes the smooth development of professional teaching and influences its quality.

In the summer of 2004, Li Jiayang, a professor of Tongji University, organized the activity of "Perception of the Sketch Creativity Camp", making a stir in the arts circle, especially in the fine arts education circle. The teaching idea of Professor Lin is peculiar and creative, having challenged the traditional sketch teaching model. The purpose of "Creativity Camp" is: learn according to the demands of the time; emphasize the training of imagination and creativity on the basis of skill expression and the improvement of aesthetic accomplishment; research how to better serve the society according to the market demand. The design is carried out by human beings, so is the result. It is necessary to consider the perceptual law and aesthetic principle of people.

\section{METHODS AND WAYS OF THE EXPERIMENTAL CREATIVE SKETCH TEACHING}

In the design field, as the forerunner of modern design, early in the 1920s and 1930s, Bauhaus had broken through the traditional sketch focusing on the "imitation theory", generating the design and creative sketch. On one hand, the course of experimental creative design sketch follows the principle of "perception education" of Bauhaus and tries to build the visual perception basis corresponding to the modern design concepts and methods; on the other hand, a unique 
training method with integrated form and ordered structure will be formed on the basis of visual thinking.

The basic guideline of the experimental creative sketch teaching is to stimulate students' enthusiasm, sensibility, excitement and the desire to explore the painting process comprehensively with various means in teaching. Teachers participate in it, enlighten and guide students. In the classroom teaching, teachers and students are equal in status. Teachers should not look down from a height and arbitrarily replace students' thinking, but strengthen the interaction with students, guide them through discussion, dialogue and enlightenment at different stages. The integration of dialogue and thinking in teaching affords for thought, contributing to a vivacious atmosphere.

Compared with the traditional sketch teaching, the sketch teaching from still life to human body in the experimental creative sketch teaching is different. In painting the still life, the experimental creative sketch teaching bases on the techniques of traditional sketch, pays attention to the training of super-realistic ability, and breaks the routine in tool materials, thought and approach. Imitation and repetition are not advocated in it. It combines long-time and short-time assignments, in-class and after-class assignments, and the assignment with extremely free imagination and realistic assignment without freedom. In the whole process, teachers and students are equal in status. Teachers inspire students' potential to the fullest. In the exploration, pleasure and anguish, failure and success coexist. Students are very excited and concentrated, contributing to the novel assignment and the expansion of scope of realistic painting. In sketching the plaster head portrait, students get rid of the traditional modes and methods, disintegrate and recombine the picture to create interesting forms and achieve distinctive effects. For example, on the basis of having completed the realistic sketch, disintegrate, change and paste it to create a visual impact. In figure drawing, carry out super-realistic depicting for the ultra conventional standard-sized and pocket-size head portraits, disintegrate, recombine and associate, creating contradictory or vague sense of space, breaking the integrity or furthest embodying the painting factors, or changing the supernormal proportion variation on visual sense through lights, or introducing the plane composition to feel the object and make the picture more creative.

The experimental creative sketch doesn't rigidly adhere to the real form but break through and innovate in many aspects, especially the expression form and ideographical expression. Compared with the sketch of "imitation" form, the creative sketch will express the emotions and information of the creator through specific visual modality. It has practical significance in conveying the function of product designed, exhibition information in display design, the graphics in visual communication design and the "symbols" in the building design. The "significant form" proposed by Clive Bell means a common aesthetic feature existing in the artistic creation if it has corresponding essential components to realize an independent art world. The "significant form" is a potential, centralized and high level embodiment of the artistic vitality. Various teaching methods can be applied. In the experimental creative sketch works, the integrated using of material medium, namely the physical support of expressing the creativity of works is all-embracing. Therefore, it is the distinctly important links in the creative practice of modern sketch to fully realize and exert the physical property and aesthetic value of material media, creatively discover and use different material media to design pictures of different themes, such as the arrangement of dot, line, geometric figures as well as the negative space. In training, take the plane modality, three-dimensional shape and spatial form as the visual basic platforms of sketch creativity, to recreate the plane illusion, three-dimensional illusion, motion illusion or thinking illusion of the visual modeling. Students freely find and choose things in life and devote to choosing, clipping and extending with creativity, replace pencils and charcoal pencils with ink brush, ink, chalk, crayon, glue, sandy soil and newspaper and integrate the collage and copy with portrayal. Organically combine the perception of painters and reason, regard things as an image related to the thinking concepts and an abstract structure free from the external restrains. Things in real life are unchangeable. In order to combine the ideal with reality, it is necessary to recreate the things portrayed through the two-dimensional space, break through and innovate on the basis of the primary form and shape the distinctive "picture in the heart".

The eternal pursuit of modern sketch teaching is to protect and develop personal unique quality, feelings and intelligence, explore and know self-awareness, seek and build language and image. The training of basic skills is to train the ability of artistic creation, break through the traditional sketch mode and expand the conception, exploration and practice aiming at the thinking mode, paying attention to the all-round extension of thinking with the purpose of personality reflection. Think about problems and feel the world independently, to seek the unique viewing angle and way of thinking, art language and technique of expression. The spirit, connotation and expression matter in art.

\section{The Formation of CREATIVE Styles of THE EXPERIMENTAL CREATIVE SKETCH}

The experimental creative sketch pays attention to the process, playing a positive role in training the creative thinking in design sketch. It advocates the full exertion of personal subjective initiative. Designers feel and understand the described things in a relaxed, pleasant, natural and harmonious state and choose the proper expression forms. They don't have to abandon the unique artistic imagination and description methods produced in design because of the "stated objective". Moreover, designers should be brave to abandon the strongest first impression or get rid of the thinking in practical observation, seek the essence of nature and develop the potential in creativity; depend on the individualized perspectives and create unique artistic imagination. The interest and charm are created by accident; the realm is established in a moment. The observation and thinking of individualized design sketch will be eliminated because of the importunity of accordance. Aiming at the negative effects brought by the representation form of "imitation" or "copy" in the modeling thought and model creation of art and design, the experimental creative sketch bases on the characteristics of art and design, emphasizes the new idea in creativity and 
modeling and finds the modeling approaches with different forms, styles and themes, rationally teasing and analyzing the visual information and creating new modeling through sketch. It is the basic requirements of sketch teaching full of artistic creativity.

\section{CONCLUSION}

The essence of experimental creative sketch teaching is the art breaking the routine instead of the science to establish the law. Effective teaching methods must be used to improve students' basic skill and thinking ability, give them high degree of freedom and complete independence in the whole teaching process, making them unconstraint. Therefore, it is the primary condition to express human feelings through training students' independent personality and free soul. However, the high independence of painting doesn't mean the endless expansion of individual consciousness. The ultimate goal is to fully express the artistic sincerity, depending on our rigorous and scientific educational philosophy. The real experimental creative sketch teaching will update the educational thought, change the teaching conception and reform the traditional teaching model.

\section{REFERENCES}

[1] Xin Huaquan. Morphological Tectonics, Chinese Academy of Fine Arts Press, 1999

[2] Wang ZHongyi, Xu Jiang. Walking from Sketch to Design, Chinese Academy of Fine Arts Press, 2002

[3] Li Xiangei Editor-in-chief, Wang Mingyi, Wu Zhenhan write, Course for the Fine Arts Specialty in Normal Universities -Design Sketch, Jiangsu Fine Arts Publishing House, 2006

[4] Lin Jiayang, Feng Junxi. Design Sketch, Higher Education Press, 2005

[5] Lin Jiayang, Design Innovation and Education, Beijing Sanlian Publishing House, 2002

[6] Wang Shouzhi, World Plane Design History, China Youth Publishing House in Beijing, 2002. 